\title{
A novel method of papilla fixation for difficult biliary cannulation without using a pancreatic duct guidewire: non-guidewire fixation method
}

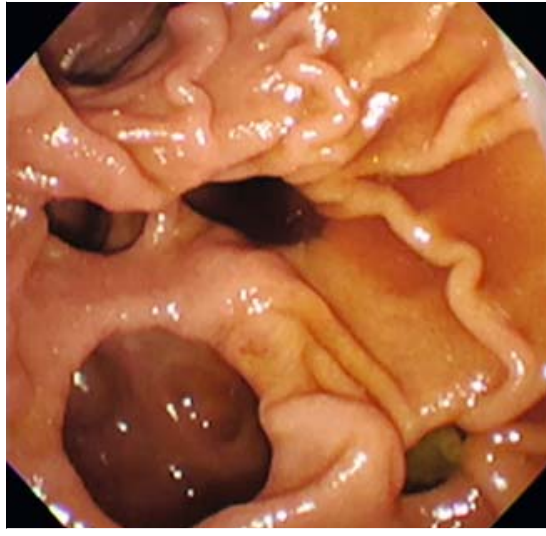

- Fig. 1 Biliary cannulation in a patient with periampullary diverticula is sometimes challenging due to high mobility and an unusual orientation of the papilla.

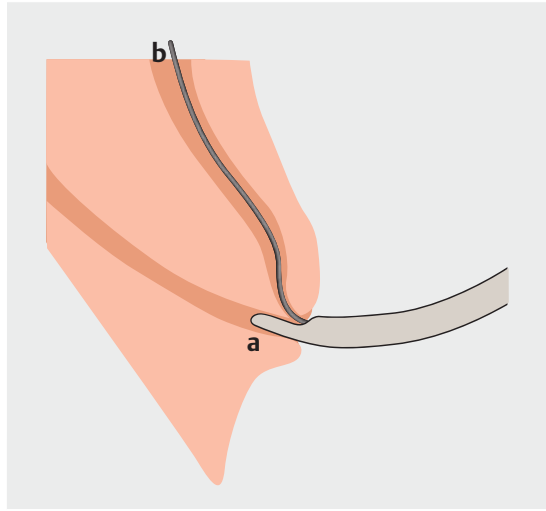

- Fig. 3 A schematic representation of this novel method. Initially, only the tip of the uneven double-lumen cannula (UDLC) (a) is inserted into the papilla for fixation, and biliary cannulation is attempted with the guidewire from the proximal lumen. The angle-shaped guidewire is manipulated vertically (b).

Biliary cannulation in patients with periampullary diverticula is challenging due to high mobility and an unusual orientation of the papilla. Although papilla fixation using a pancreatic duct guidewire (PGW) has been performed in such cases, the procedure requires the placement of a guidewire in the pancreatic duct and takes times [1-4] ( $\triangleright$ Fig. 1). The risk of PGW-induced postoperative pancreatitis has also been reported [5]. To overcome

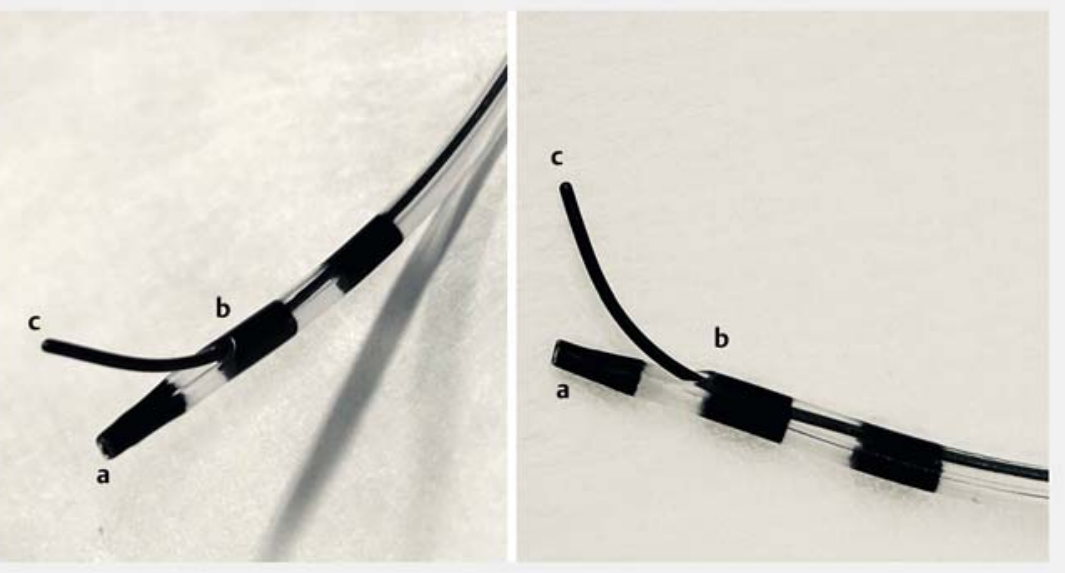

- Fig. 2 Illustration (left image) and photograph (right image) of the uneven double-lumen cannula (UDLC; PIOLAX, Tokyo, Japan), which has two lumens measuring 0.025 (distal, a) and 0.035 (proximal, b) inches in diameter. The orifice of each lumen is uneven, thereby creating a channel within the tip. The proximal lumen opens upward, allowing the angle-shaped guidewire to be manipulated vertically (c).
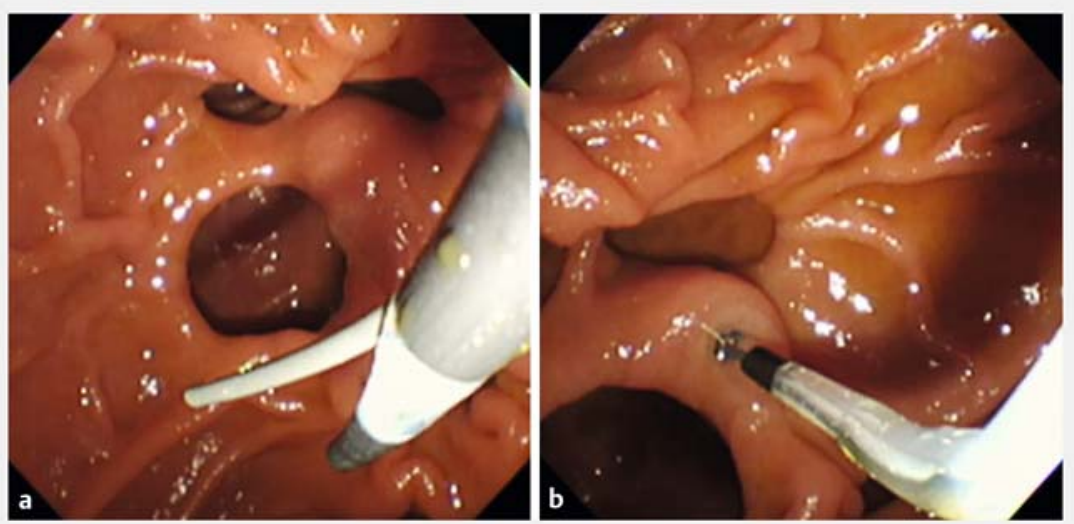

Fig. 4 Use of the uneven double-lumen cannula (UDLC). a The tip of the UDLC and angleshaped guidewire from the proximal lumen can be seen. $\mathbf{b}$ Initially, only the tip of the UDLC is inserted into the papilla for fixation.

these challenges, we developed a novel method for difficult biliary cannulation without using a PGW, involving papilla fixation with a unique double-lumen catheter

A 68-year-old woman presented with obstructive jaundice due to pancreatic cancer. Biliary drainage was attempted. However, biliary cannulation was difficult because the papilla was highly mobile with many periampullary diverticula and the orientation of the papilla was unusual. The contrasted pancreatic duct was too short for proper insertion of a PGW to fix the papilla.

We used an uneven, double-lumen cannula (UDLC; PIOLAX, Tokyo, Japan); the diameters of the lumens are 0.025 (distal) and 0.035 (proximal) inches. The orifice of each lumen is uneven, and the proximal lumen opens upward, allowing vertical manipulation of the 

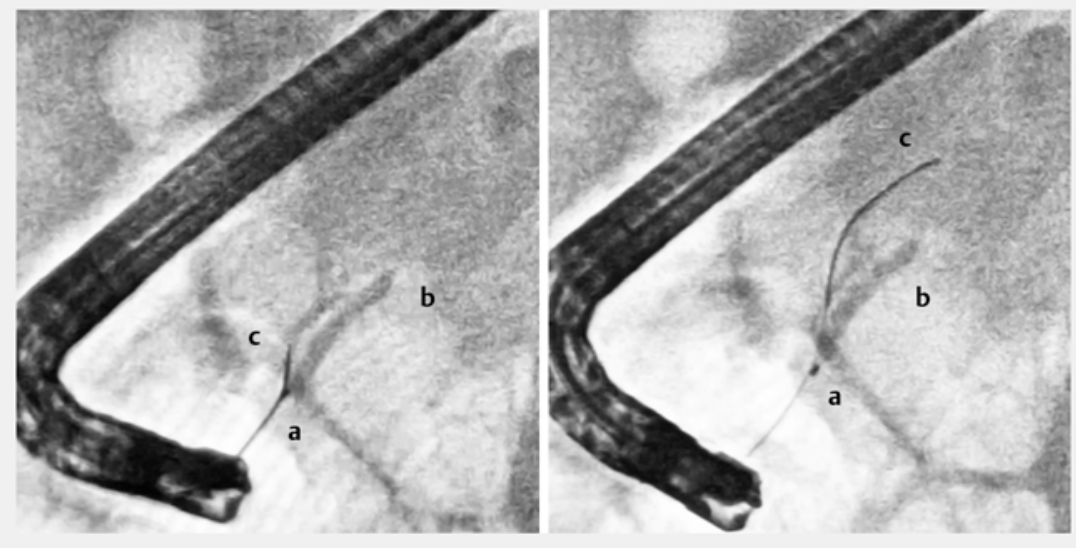

- Fig. 5 Fluoroscopic images showing papilla fixation (left image) and biliary cannulation (right image). The fluoroscopic marker of the uneven double-lumen cannula (UDLC) (a) and contrasted pancreatic duct are visible (b). The angle-shaped guidewire from the proximal lumen (c) is used for biliary cannulation. The guidewire is manipulated vertically, and biliary cannulation is successfully achieved.

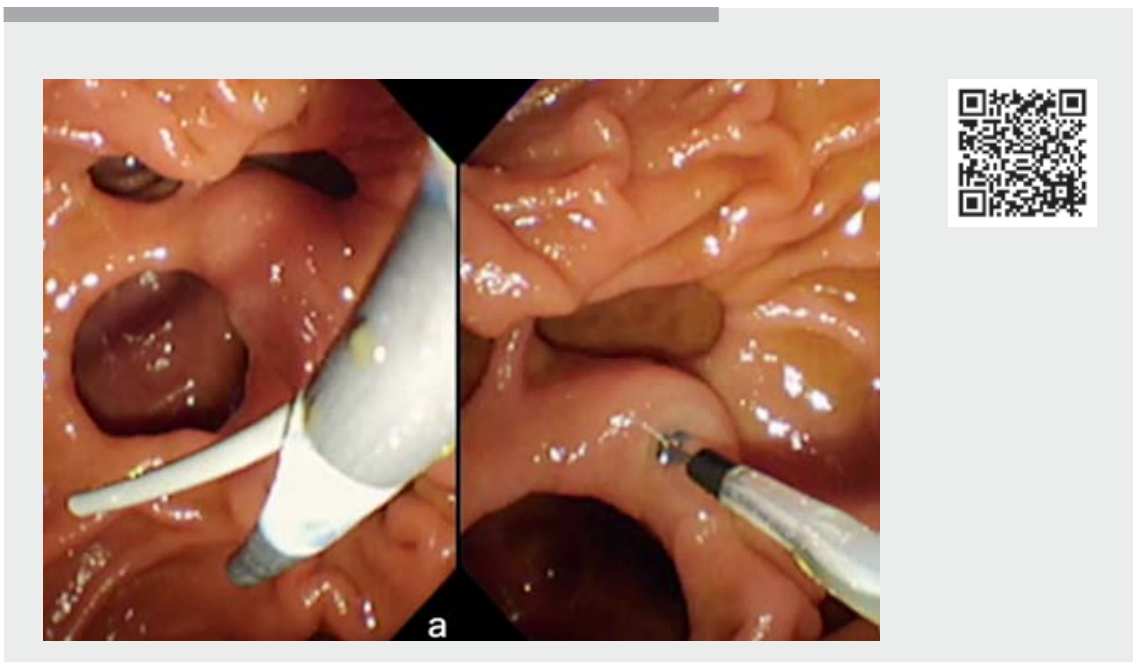

$\checkmark$ Video 1 A novel method of papilla fixation for difficult biliary cannulation that does not require a pancreatic duct guidewire but instead uses a unique double-lumen catheter. This method may be useful for biliary cannulation.

angle-shaped guidewire. This feature is considered anatomically favorable for biliary cannulation, using the cannula tip for fixation of the papilla and the proximal lumen for guidewire manipulation ( $\bullet$ Fig. 2).

Initially, only the tip of the UDLC is inserted into the papilla for fixation, and biliary cannulation is attempted using the 0.025 -inch angle-shaped guidewire (Visglide2; Olympus, Tokyo, Japan) from the proximal lumen. The guidewire is manipulated vertically, and biliary cannulation is successfully performed ( $\nabla$ Fig.3,
This novel concept of papilla fixation can reduce the time required for PGW insertion, and the risk of PGW-induced pancreatitis, and may be a useful option for biliary cannulation.

Endoscopy_UCTN_Code_TTT_1AR_2AK

\section{Competing interests}

The authors declare that they have no conflict of interest.
The authors

Mamoru Takenaka1 ${ }^{\circledR}$, Koichiro Kawano², Reiko Kawano², Takao Katoh ${ }^{2}$, Katsuhisa Nishi $^{2}$, Masatoshi Kudo ${ }^{1}$

1 Department of Gastroenterology and Hepatology, Kindai University Faculty of Medicine, Osaka-Sayama, Japan

2 Department of Gastroenterology and Hepatology, Hyogo Prefectural Awaji Medical Center, Sumoto, Japan

\section{Corresponding author}

\section{Mamoru Takenaka, MD}

Department of Gastroenterology and Hepatology, Kindai University Faculty of Medicine, 377-2 Ohno-Higashi, Osaka-

Sayama, 589-8511, Japan

mamoxy045@gmail.com

\section{References}

[1] Gonzalez JM, Debourdeau A, Barthet M. How to facilitate cannulation of an intradiverticular papilla: a technique with two devices in one channel using pediatric forceps. Endoscopy 2019; 51: 1095-1096

[2] Kim KH, Kim TN. A new technique for difficult biliary cannulation using endobiliary forceps in a patient with a periampullary diverticulum. Endoscopy 2017; 49: 824-826

[3] Myung DS, Park CH, Koh HR et al. Cap-assisted ERCP in patients with difficult cannulation due to periampullary diverticulum. Endoscopy 2014; 46: 352-355

[4] Takenaka M, Minaga K, Kudo M. Cannulation method for intradiverticular papilla with long oral protrusion using biopsy forceps for axis alignment. Dig Endosc 2018; 30: 700701

[5] Nakai Y, Isayama H, Sasahira N et al. Risk factors for post-ERCP pancreatitis in wireguided cannulation for therapeutic biliary ERCP. Gastrointest Endosc 2015; 81: 119126

\section{Bibliography}

Endoscopy 2022; 54: 101-102

DOI $10.1055 / \mathrm{a}-1376-6315$

ISSN $0013-726 \mathrm{X}$

published online 5.3.2021

(c) 2021. Thieme. All rights reserved.

Georg Thieme Verlag KG, Rüdigerstraße 14, 70469 Stuttgart, Germany

> Fig. 4, > Fig. 5, > Video 1). 